\section{Briginal Communication.}

\author{
SEVERE NEURALGIA OF THE UTERUS, FOL- \\ LOWING PREMATURE LABOUR: EARLY \\ DISCHARGE OF LIQUOR AMNII.
}

By Williant Henry Day, M.D., L.R.C.P.Lond., late Assistant-Surgeon H.M. 3rd Foot.

$\Lambda$ raDy, aged $3 \pm$, tall and well formed, the mother of three children, was delivered at the seventh month of a female child, which died at the end of six days, after several convulsive paroxysms. The child weighed at birth only one pound and a quarter; its limbs were flaccid and shrunken, and altogether it was in a very feeble and languid state. A portion of the placenta and membranes were putrid. The labour was an easy one; the placenta being expelled into the cavity of the vagina, and at once removed, in order to insure a well contracted uterus. Great exhaustion followed the birth, the surface becoming deadly pale and cold, and the pulse almost imperceptible. Labour pains set in twenty hours before the birth of the child ; but they did not become of a decidedly expulsive nature until four hours preceding delivery, during which time warm brandy and water was repeatedly given.

About the third month of utero-gestation, the patient, after strong exercise, had an attack of uterine hæmorrhage, which yiclded to rest and the usual remedies; but a drain of clear fluid from the uterus continued for some days, and, according to her statement, perceptibly reduced the size of the abdomen. At the fourth month, hæmorrhage recurred, of a more active and persistent character; and as the sanguineous discharge les. sened, the colourless drain became more apparent. At the fifth month, this transparent discharge was so great, that I can only liken it to the sudden rupture of the membranes when protruding through the os uteri and filling the vagina at an ordinary labour. After rest in bed and other appropriate treatment, these grave symptoms vanished, but returned in a few days; and, although the loss was now inconsiderable, it never entirely left the patient till the hour of her confinement.

About every third day, a small clot of blood was dis. charged, mixed with serous fluid. The bowels were acted on by a simple enema of warm water, and the vulva and leypogastrium well sponged with cold water night and morning. The patient lay on a mattress, with the pelvis elevated. She had now become much reduced in flesh and strength. She was alarmed, worn, and exsanguine, often hysterical, and afraid of her approaching confinement. The pulsation of the fœtal heart was distinctly heard in the left iliac region, and fotal movement felt by the patient. The os uteri was soft and moderately dilated.

The patient progressed satisfactorily till July 25th, 1861 (nine days after delivery), when she complained of feeling very weak and languid, with severe pain in the back, shooting round to the lower part of the abdomen; her appetite was poor and capricious, and her nights wakeful and restless. She was ordered four ounces of port wine, milk and arrow-root diet, and a mutton-chop as she fancied it; also a sixth part of the following mix. three times a day.

R Tincturæ cinchonæ comp. そ̧ss; spiritûs ammon. aromat. $3 \mathbf{j}$; aquæ puræ ad $3 v j$. M.

She was also directed to take four grains of extract of hyoscyamus every night.

July 29th. She was not so well. The countenance was pale and exhausted; there were dark areolæ round the eyes; and sensibility generally was diminished. There was slight headache over the right eyebrow and temple, sometimes occupying the whole forehead. The skin was cool and moist; pulse regular, but weak, 68 per minute. The pain in the back was somewhat less than it had been; it was now principally sacral. The nates were painful and tender; and this tenderness was increased on pressure; it was rather more between the trochanters and tuberosities of the ischia, and extended, diminishing in severity, down the back and front of the thighs. There was no swelling of the legs or ankles; on the contrary, the extremities were much wasted from the privation of pure air and exercise, to which she had been much accustomed. The abdomen was tympanitic and tender generally; the most painful spots being over the hypogastrium and left iliac region, where the pain was deeper seated than about the umbilicus, though there was pain in the right groin also; and she was troubled with a good deal of flatulence. In the recum. bent posture, the patient had moderate ease and freedom from much suffering; but, on attempting to rise or turn in bed, or trying to put her feet to the ground, the pain came on. On a vaginal examination, the canal was found cool and moist. The uterus descended perhaps a little lower than was normal, and the cervix was somewhat enlarged and elastic. This was especially the case with the anterior lip. There was no indication of hardness. The os uteri was slightly open; and there was a little pale discharge. When the point of the finger was driven against it, it caused pain, which was felt more internally than at the part struck. She complained of much pain at the lower part of her back. The bowels were rather costive. She took her allowance of food and wine. The bark mixture was continued, and the following aperient draught ordered every other morning.

R Pulveris rhei, magnesiæ carbonatis, āä gr. xv; spiritûs ammon. aromat. $3 \mathrm{ss}$; tincturæ cardam. comp. $3 \mathrm{j}$; aquæ menthæ piperitæ $3 \mathrm{x}$. M. Fiat haustus.

July 31 st. She was much the same. She thought the pill at night caused her to be more restless, without relieving pain; it was therefore omitted. A fourth part of a liniment, containing an ounce of compound camphor liniment and the same quantity of tincture of belladonna, was ordered to be rubbed into the body night and morning.

Aug. 2nd. The abdominal pain was increased, and pressure aggravated it, as well as the slightest movement. The groins were aching and painful, and the hypogastrium especially so. The urine was copious and healthy. The patient fancied there was rather more fulness on the left side; but it was not very apparent. The pain in the back was higher up and more severe; the os uteri was more open, but excessively tender when touched; an aching, dragging pain continued for some time afterwards. There was a little more discharge. She had passed a better night. The bowels did not act without the aperient draught; and then the pelvic pain was always aggravated. The wine was increased to six ounces; the bark mixture was omitted; and a sixth part of the following ordered to be taken three times a day.

Bo Ferri et quinæ citratis $3 \mathrm{ss}$; tincturæ aurantii 3 iij ; tincturæ zingiberis $\jmath^{\text {ss }}$; aquæ ad $\jmath_{\mathrm{vj}}$. M. Fiat mistura.

Aug. 3rd. There was no improvement. Agonising pain came on severely about 4 A.M., and continued more or less during the night. She was now free from pain in the body, which was less swollen; but there was great tenderness in the hypogastrium and groins. Conversation had brought on headache. The tongue was quite clean; pulse 68 , very small and weak. The urine was turbid, and she was low and desponding. The pain generally came on at about seven or eight o'clock in the evening. A turpentine stupe was ordered to be applied to the abdomen every night; and a warm water injection, with laudanum, to be thrown into the vagina three times a day. The steel mixture was ordered to be 
omitted, and a sixth part of the following to be taken every four hours.

B Etheris chlorici, spiritûs atheris nitrici, ãa $\breve{j}$ iss; liquoris morphiæ hydrochlor. $3 \mathrm{ss}$; mist. camphor: žrj. M. Fiat mistura.

Aug. 5th. The tenderness was greater than ever over the hypogastrium ; and the patient was completely helpless, being unable to move or turn herself in bed. There was severe headache, especially over the right eye. The back at the lower part was very painful, and the least pressure was agony. The fomentations gave no relief The countenance was very pale and prostrate; pulse 62 . She was evidently getting worse. The wine was increased to eight ounces daily, and nourishment ordered to be taken ad libitum; a belladonna plaister to be applied to the sacrum; and the following draught to be taken every morning and evening.

Bo Quinæ disulphatis gr. ij; acidi sulphurici diluti miv : tincturæ aurantii, syrupi aurantii, ảa $\bar{j} j$; aquæ ad z̧iss. M. Fiat haustus.

Aug. 7th. The pain was every where diminished; she was better, and looked more cheerful and animated She had a good appetite, and took her allowance of food and wine. The pain over the hypogastrium was very considerable on pressure, and prevented her from getting rest at night. A small blister, of the size of a watch glass, was ordered to be raised over the hypogastrium and left iliac region, and to be dressed with an ointment containing two grains of muriate of morphia to one drachm of lard. The wine and tonic were continued.

Aug. 10th. The patient, who desired to apply the blistering fluid herself, made a large extent of surface very sore and tender. An examination per vaginam gave much less pain; the os uteri was more open, but scarcely tender to the touch. The general health was much improved.

Aug. 12th. She was suffering from a good deal of vesical irritation; the urine throwing down a lithic acid deposit, and the surface of the body being very sore from the application. There was severe pain in the loins; and the urine was highly acid, scanty, and irri. tating. The pulse was not accelerated, but she complained of languor and flatulent dyspepsia. She was ordered to take the following draught every four hours, omitting the other medicine.

Bo Potasse bicarbon. gr. $x v$; xtheris chlorici $m x$; spiritûs retheris nitrici $m x v$; tinctura cardam. comp. $\mathfrak{j}^{\text {ss }}$; aque ad $\tilde{\jmath}^{\text {iss. }}$ M. Fiat haustus.

Aug. 22nd. The irritation had gradually abated to the present, and it was now only slight; but the patient had suffered severely from the effects of the wide. spreading blister and the sharper recurrence of head ache since the omission of the steel medisine. The urine was still acid, and the pulse weak and slow. Her appetite was good, and she slept well. She left the next day to go to the seaside, with directions to continue the following mixture as prescribed. She was just able to stand, but could not walk a step without support.

Bo Ferri ammonio-citratis, potassæ bicarbon., ãa 3 iss ;

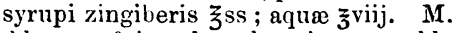

One tablespoonful to be taken in two tablespoonfuls of water, three times a day.

From this time the improvement was marked and gradual. On her return, at the expiration of a fortnight, she was able to walk without assistance, and was merely suffering from debility. The citrate of iron and quinine was substituted for that ordered on the 22nd ult., which, with a full allowance of wine and a nutritious diet, she took for six weeks, when her recovery was complete.

Remarks. This case is both instructive and interesting, it being difficult to say whether the disorder was inflammatory or neuralgic at the commencement, the symptoms changing their type so frequently; one day looking like inflammation, and another pointing to derangement of the nervous system alone. The case is analogous to those described by Gooch, Dewees, Montgomery, Churchill, and others, who, whilst they admit the occurrence of the disease, differ as to its pathology. Some regard it as a chronic form of inflammation; and certainly the local symptoms at one period were very like it in the case in question; others ascribe it to intestinal irritation; and not a few to pure neuralgia.

The early cessation of uterine discharge, and the extreme pain on pressure; the swelled abdomen and the tendency to constipation; rather indicated some degree of inflammation; and it was not until the tonic treatment was persisted in that its nature became clearer. I was led to give this treatment a fair trial, on account of the exhausting illness to which the patient had been so long subjected previously to ber confinement. Her severe headache mostly attacking one side, her clean large tongue and languid circulation, induced me to persevere in the treatment, though for a few days the ab. domen was so tender, and the pain seemed spreading upwards from the pelvis, that I was almost tempted to apply a few leeches, which would probably have aggravated the mischief. Viewing these cases, as some have done, in the light of a chronic inflammation of the uterus, I might have committed what I now consider would have been an error. The great amount of depression decided me to support the bodily powers at any risk.

The blistering and sedative ointment materially assisted in relieving the abdominal pain, although the accidental extensive vesication produced great irritation and annoyance for some days. The value of a liberal and nutritous diet is well exemplified, the pain and prostration decreasing with a stronger digestion, and the worst features of the case departing under the free use of wine and tonics.

One other circumstance of note was the draining of liquor amnii. It commenced at the third month of utero-gestation; it increased a month later; and it recurred slightly at intervals till within a month of delivery. The patient believed it impossible for her to "go her time," as, to use her own words, " the water was coming away."

Singularly enough, I had under my care at the time a women to whom a similar accident happened. In this case, the patient, aged 36 years, the mother of four children, was attacked at the fourth month of her pregnancy with a colourless loss, which soon subsided. It occurred again at the sixth month; and when I visited her at this time, she had been frightened about some trifling family matter, and this had brought on a return of the discharge, and with it irregular labour pains. The loss was so great that the fluid had run through the bedclothes on to the floor. When the uterine contraction came on, the os uteri dilated and the fluid escaped; but neither the membranes, nor any portion of the child, could be felt presenting. The abdomen was becoming more flaccid; and she was suffering most excruciating pain in the head and lower part of the back. Her condition was truly deplorable, and, I considered, perilous. I applied a broad binder round the body to support her pendulous belly; and prescribed a full dose of opium, which soon relieved the pain in the head, and calmed the nervous excitement. This was followed by some refreshing sleep; and on the following day, as she was better, and the discharge arrested, I ordered her quinine in two grain doses, with some mineral acid three times a day. She did tolerably well till the eighth month, when I was summoned to attend her in her confinement. The head was presenting, and the os uteri dilated to the size of a crown-piece, and the pains were regular and forcing. After staying with her three hours, the labour making no further progress, I administered a dose of opium and left her, with directions to be sent for if she became worse. Two days later, the woman was sitting up, and was not confined till another month 
had expired.* Her labour was quick and natural, and the membranes and placenta were quite healthy. She is now suckling a fine infant, and doing well.

What was the source of the fluid in these cases? It evidently came from the sac of the amnion in the first case; and in the second case, it appears to have had a similar origin.

Excessive discharges are spoken of by writers on mid. wifery as taking place in pregnant women from the va. gina and membranes of the ovum to the extent of many quarts; but the sudden and profuse loss, followed by shrinking of the abdominal parietes, leave little doubt but the cavity of the amnion furnished the fluid in the two cases under consideration. In the first case, the patient did not go her time; the infant was puny and feeble, and a part of the placenta and membranes diseased, as might have been expected; but in the latter case, it is remarkable that the woman in her weak and delicate state should have dragged through the full term of utero-gestation, and then have given birth to a healthy child. She never remembered to have been so large in her previous pregnancies, and often expressed a dread of having two children at a birth. The otber patient also said, at an early period of her pregnancy, that her size was much greater than formerly.

A dropsical condition of the amnion would account for the patient's great size. During gestation, she suffered severely from painful flatulence and dyspepsia, hiccup, short dry cough, and great cedema of the legs and ankles. Her breathing was so embarrassed that she frequently sat up during the night, or propped herself up with pillows, from fear of lying down.

During my limited experience I had never before met with two such cases; and I must own that they entailed considerable anxiety.

\section{RETROVERSION OF THE GRAVID UTERUS: THE BEST POSITION DURING ITS REDUCTION.}

By Thomas Skinner, M.D., Liverpool.

The Association did me the honour to publish in the Journal for 1860 a series of papers on Retroversion of the Gravid Uterus. As objections have been made in reference to the position of the patient recommended in my essay, as well as to the hand being introduced into the rectum rather than into the vagina, I must beg a little space to answer these same objections.

The position which I have put forth, and which I still maintain is the best, is " the patient upon her left side, the pelvis well raised, the shoulders low, and the thighs as much flexed upon the abdomen as possible." (JourNaL, 1860, p. 949.) It is objected to this position that it ignores the aid of gravitation; but I cannot see how it does so. I think that the position sufficiently favours gravitation; and that in the great majority of cases it will be found quite enough so for all practical purposes.

It has been recommended in preference, that the patient should be placed with the lower extremities in bed, the pelvis over the side of the bed, and the elbows and hands on the floor; and the observation has been made that this position can be maintained for a considerable period. I cannot agree in this opinion, as in Mr. Wall's and many other cases where this position was tried, the taxis had to be stopped and renewed at intervals, the position being found to be both irlisome and tiresome. This position is further open to the following objections, namely, that of raising unnecessary fears on the part of the patient; of being most repulsive to the natural mo-

* See an interesting case of Retrocession of Labour, by Dr. Charien, recorded in the Half-Yearly Abstract of the Medical Sci ences, vol. $\mathrm{xxx}, \mathrm{p} .256$. desty of even the most callous of the sex, and the fact, that the reduction bas been and can be easily accomplished without it; besides, to invert a female in the puerperal condition should never be done if it can be avoided, as it determines the blood to the head and chest, harasses the breathing, and entirely prevents the aid of anæsthetics.

With regard to the statistics of the point at issue, $I$ may state that I have collected all the facts on record connected with seventy cases of retroversion of the gravid uterus; of these, nine were placed with the lower extremities in bed, and the upper extremities on the floor. In five of them, the taxis was successful, while in four, it entirely failed; of the four failures, three died. In the remaining sixty-one cases, although the position assumed is not positively stated in all of them, yet there are sufficient facts to lead me to infer that they were not inverted. They were placed chiefly upon the left side, upon the back, and a few of them on "allfours." In the great majority of these sixty-one cases, the taxis (chiefly on the left side or back) was successful; and in a few of them, catheterism alone, without the taxis, was sufficient to reduce the displacement. In fourteen cases, the patients died. Add to these statistical facts, that $I$ have myself repeatedly reduced the retroverted gravid uterus with ease; and that I have never employed any other position but the one I have recommended (except once in a difficult case, where I placed the patient on ber back); and I think that we have sufficience of guarantee, not only of the success attending the practice; but of evidence that the profession hitherto have not generally adopted the practice of inverting the patient; nor do I think that they are likely to do so even now, except under the pressure of circumstances, or as a dernier ressort.

It has been argued, that inverting the patient is best, because the uterus is pear-shaped. Let me remind those who think so, that the uterus begins to lose this form about the third month; that between this term and the fifth month (the most prevalent period for the occurrence or the detection of retroversion), it gradually becomes spherical; after which, and up to the full term of gestation it again becomes pyriform.

Lastly, objections have been made to the hand being slowly introduced into the rectum (as a last resource, and when all other means have failed, puncture of the bladder or uterus beirg excepted), and there seems to be some doubt entertained as to the possibility of doing so. There need be no doubt, as the operation has already been done by several of the most distinguished members of the profession, and with comparative success; as instance, in Mr. Weir's case, when all the most approved methods had been attempted in vain. The operation, or a somewhat similar one, is performed very frequently for fissura ani; I have seen Professor Simpson do so; and I have repeated the operation myself with the greatest ease. It is not nearly so difficult an operation as à priori we might be led to suppose, especially when we resort to the use of certain adjuvants I have alluded to in my essay, namely, steaming, the warm bath, inunction, veriesection, tartar emetic, opium, and more particularly the use of chloroform.

As the rule in ordinary cases, I have recommended the first two fingers of the right hand per rectum.

Oleum Morrhum Ferratum. Fifteen parts of proto sulphate of iron are precipitated by fourteen parts carbonate of soda; the precipitate expressed; and afte $\boldsymbol{r}$ the addition of little water, digested for two hours and a half in a water bath, with two hundred and fifty parts cod liver oil. The deep brown mixture readily becomes clear in a bottle, and soon thickens on exposure to the air. The oil is said to contain about one per cent. of iron. (Amer. Jour. Phar.) 